\title{
MECHANOCHEMICAL EFFECTS OF SOME RARE-EARTH ULTRAPHOSPHATES AND REFORMING OF THEIR SURFACE FOR CATALYTIC PROPERTIES
}

\author{
HIROAKI ONODA, HIROYUKI NARIAI, HIDESHI MAKI, \\ and ITARU MOTOOKA \\ Department of Chemical Science and Engineering, \\ Faculty of Engineering, Kobe University, \\ Rokkodai-cho, Nada-ku, Kobe 657-8501, Japan
}

\begin{abstract}
Rare-earth ultraphosphates, RP5014, were synthesized, and their mechanochemical effects due to grinding were investigated by using TG-DTA, XRD, FT-IR and SEM. When the ultraphosphates were ground, their XRD peaks became smaller, their particles were flocculated to be paste, and their P-O-P bondings were cleaved to form $\mathrm{P}-\mathrm{O} \cdot \mathrm{H}$ bondings. The $\mathrm{P}-\mathrm{O}-\mathrm{H}$ bondings formed by mechanical treatment were expected to raise catalytic activities of rare-earth ultraphosphates. The ultraphosphates reformed by grinding enlarged the surface areas, the acid strength, amount of acidic sites, and the conversion of 2-propanol to propylene.
\end{abstract}

\section{INTRODUCTION}

One of the features of rare-earth phosphates is to form specific crystal structure because the ionic radii of rare-earth elements are larger than those of other metals. Ultraphosphates have the network structure which consists of the anions represented by $[P(n+2) O(3 n+5)] n^{-}(n=2,3,4,6)$. Because these anions contain more P-O-P bondings than chain and ring phosphates, ${ }^{1)}$ ultraphosphates are generally unstable for hydrolysis, and so

$\overline{\text { Received January 18, 1999; approved April 6, } 1999}$ 
there are few stable salts except for rare-earth salts. Consequently, there has been few reports about mechanochemical effects of ultraphosphates.

The reforming of solid surface gives the powder higher functional properties. There are some kinds of reforming by coating, topochemical method, mechanical treatment, ultraviolet irradiation, etc. ${ }^{2,3)}$

In this work, the mechanochemical effects of some rare-earth ultraphosphates by grinding were studied, and their mechanical reformings were attempted in order to use them as a solid acid catalyst.

\section{EXPERIMENTAL}

\section{Materials}

Each of rare-earth oxide ( $\mathrm{La}_{2} \mathrm{O} 3, \mathrm{CeO} 2$, and $\mathrm{Nd} 2 \mathrm{O} 3$ ) was mixed with phosphoric acid in the molar ratio of $\mathrm{P} / \mathrm{R}=10\left(\mathrm{R} ; \mathrm{La}^{3+}, \mathrm{Ce}^{4+}, \mathrm{Nd}^{3+}\right)$, and then the mixture was heated at $700^{\circ} \mathrm{C}$ for 20 hours. ${ }^{4)}$ The product obtained was washed with water to remove the excess phosphoric acid and dried in air.

\section{Mechanical Treatment}

Ultraphosphates ( $\mathrm{LaP}_{5} \mathrm{O}_{14}, \mathrm{CeP} 5 \mathrm{O}_{14}$, and $\mathrm{NdP5O}$ 14) were treated with grinding-mill, and a small amount of ground samples was taken out at the prescribed time interval for analyses. ${ }^{5,6}$ Samples before and after mechanical treatment were analyzed by XRD, FT-IR, TG-DTA, and SEM.

\section{Acidic and Catalytic Properties}

The surface areas of ultraphosphates (LaP5O14, CeP5O14, and NdP5O14) treated with grinding-mill were calculated from the amount of nitrogen gas adsorbed at the temperature of liquid nitrogen." Acidic properties (acidic strength and amount) were examined by butylamine titration using four indicators (Methyl red, Dimethyl yellow, Benzeneazodiphenylamine, and Dicinnamalacetone) because the $\mathrm{pKa}$ of an indicator is the factor which determined the level of acid strength of the titrated acid sites. ${ }^{8}$ Catalytic activity was measured by using a pulse type reactor directly connected to a gas chromatograph. ${ }^{9)}$ Catalytic activity was estimated from the basis of the conversion of 2-propanol to propylene.

\section{RESULTS AND DISCUSSION}




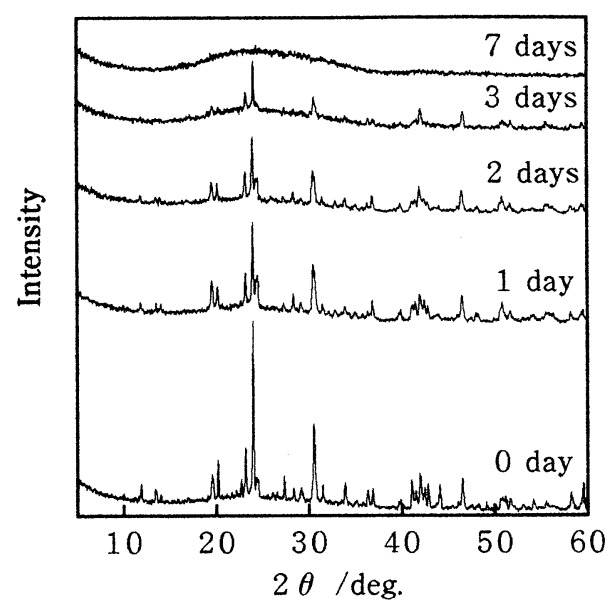

FIGURE 1 XRD patterns of $\mathrm{NdP}_{5} \mathrm{O}_{14}$ treated with grinding-mill.

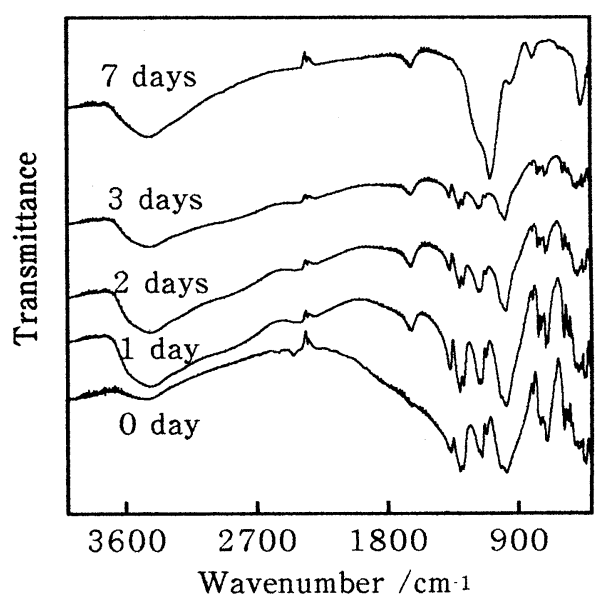

FIGURE 2 IR spectra of $\mathrm{NdP}_{5} \mathrm{O}_{14}$ treated with grinding-mill.

\section{Mechanochemical Effect}

As shown in Figure 1, X-ray diffraction peaks of neodymium ultraphosphate became smaller with the increasing of grinding time, and then the sample treated for 7 days was amorphous. Figure 2 shows the changes of infrared spectra of $\mathrm{NdP} 5 \mathrm{O} 14$ due to grinding. IR spectra of treated samples contained two new peaks at about 1640 and $3300 \mathrm{~cm}^{-1}$. These peaks were assigned to $\mathrm{O}-\mathrm{H}$ stretching vibration ${ }^{10)}$ based on adsorbed water.

Figure 3 shows TG-DTA curves of $\mathrm{NdP} 5 \mathrm{O} 14$ treated with grindingmill. Treated phosphates had an endothermic peak at $\angle 100^{\circ} \mathrm{C}$ in DTA curves. Although the untreated sample didn't have weight loss in TG curves, the treated samples have the weight loss caused by adsorbed water. The samples ground for 2 and 3 days have some endothermic peaks accompanied with the weight loss at $350 \sim 400^{\circ} \mathrm{C}$. This result indicated that the $\mathrm{P}-\mathrm{O}-\mathrm{H}$ bonding produced by grinding was condensed to P-O$P$ bonding. In XRD results of

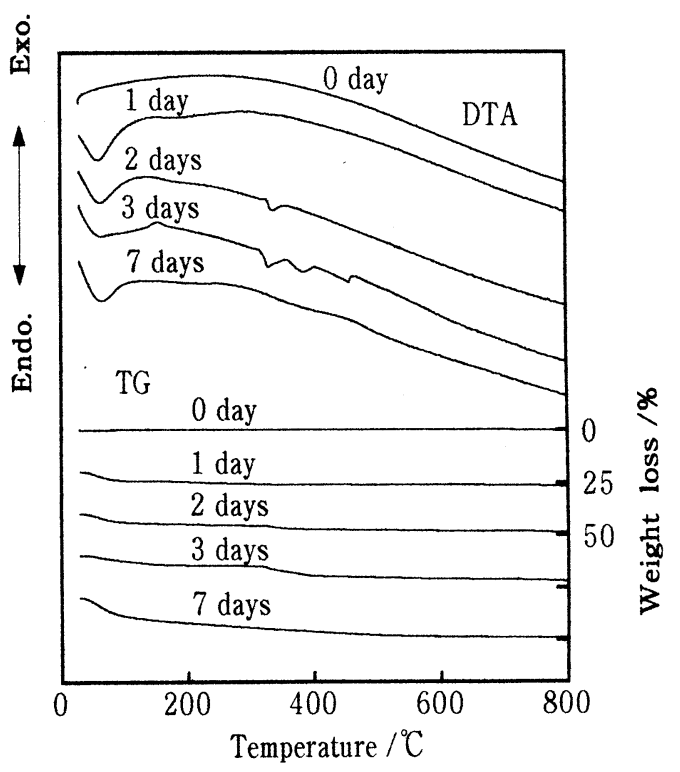

FIGURE 3 TG-DTA curves of $\mathrm{NdP}_{5} \mathrm{O}_{14}$ treated with grinding-mill. 
heated products, the peaks of neodymium polyphosphate were observed with those of ultraphosphate. The endothermic peak by condensation of the sample treated for 1 day wasn't observed, because it had little P-O.H bonding.

Figure 4 shows SEM photographs of neodymium ultraphosphate. The flocculation of samples occurred by grinding and the size of their particle became larger. The hydrogen bonding formed by the P-O-H groups served as a cohesive force.

The mechanochemical effects of $\mathrm{LaP}_{5} \mathrm{O}_{14}$ and $\mathrm{CeP} 5 \mathrm{O} 14$ were similar to those of $\mathrm{NdP} 5 \mathrm{O} 14$.

It was found from the above results that rare-earth ultraphosphates were affected greatly by mechanical treatment, that is, the grinding destroyed their crystal structure and triggered the cleavage of P-O-P bonding.
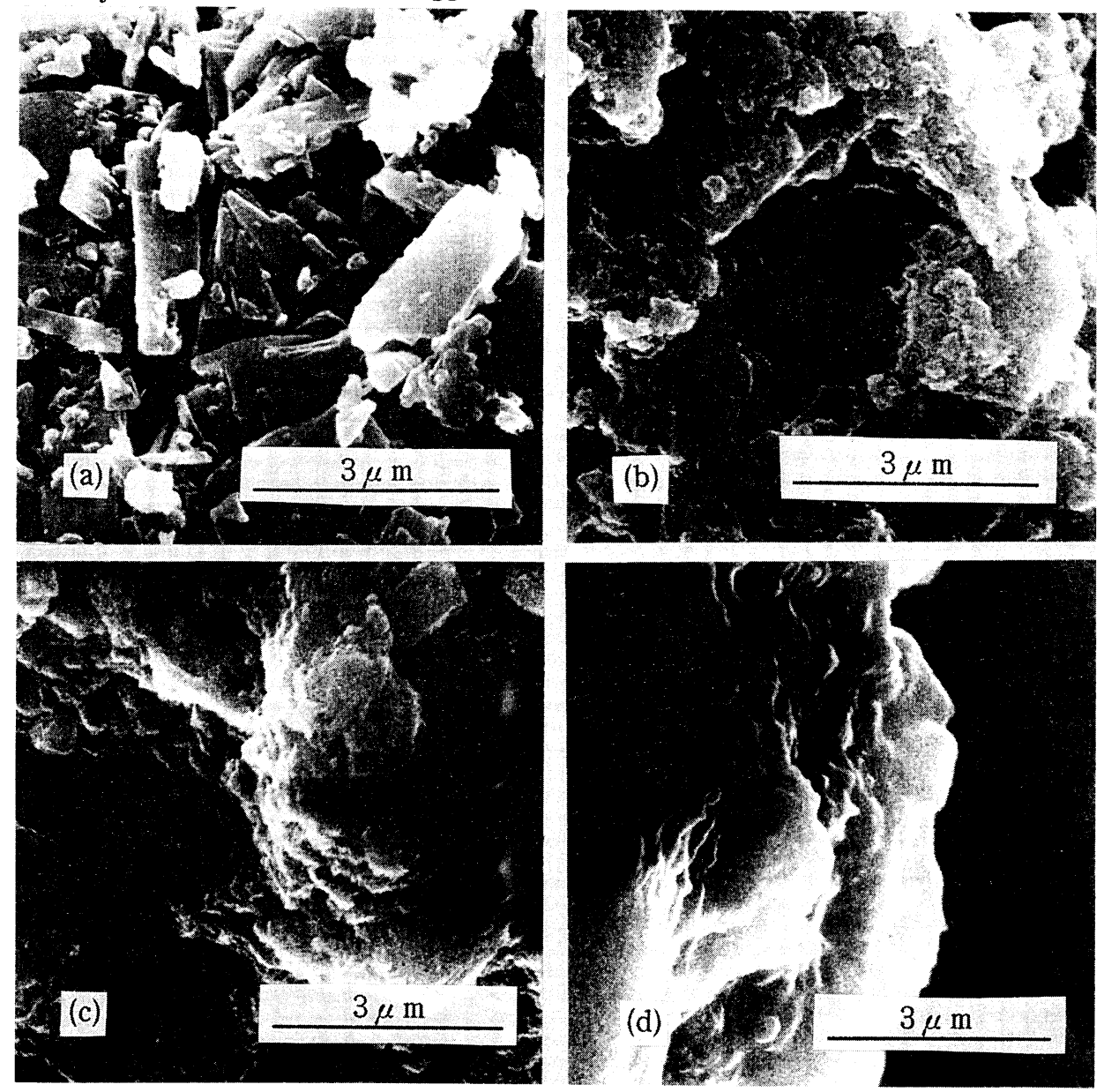

FIGURE 4 SEM photograph of $\mathrm{NdP} 5 \mathrm{O} 14$ treated with grinding-mill for (a) 0 day, (b) 1 day, (c) 2 days, and (d) 3 days ( $\times 10000)$. 
Acidic and Catalytic Properties

The formation of $\mathrm{P}-\mathrm{O}-\mathrm{H}$ bonding is expected to improve the ability of rare-earth ultraphosphate as solid acid catalyst. When ultraphosphates were ground for long time, their particles aggregated and their surface areas became smaller, and the ground sample became paste. Therefore, the surface areas, acidic properties and the catalytic activity of the samples treated for short time were investigated.

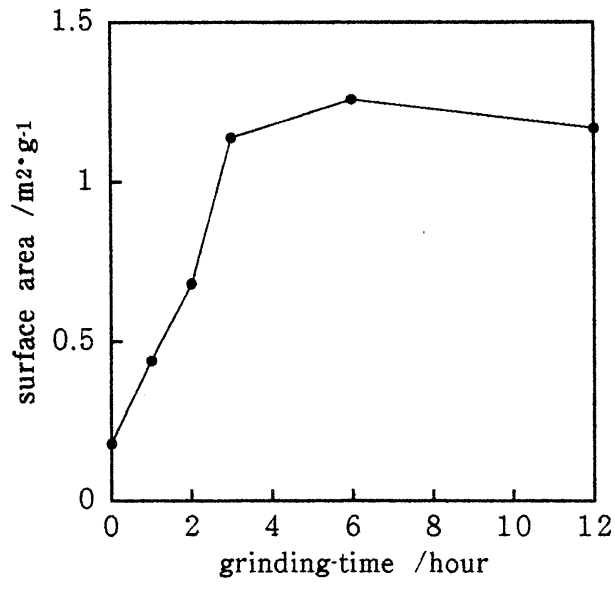

FIGURE 5 Surface areas of $\mathrm{NdP}_{5} \mathrm{O}_{14}$ treated with grinding-mill.

Figure 5 shows the changes of the surface areas of ground neodymium ultraphosphates. The surface areas of $\mathrm{NdP}_{5} \mathrm{O} 14$ became larger with increase of grinding time. The treatment of more long time made the measurement of surface area difficult because samples flocculated and became paste.

Figure 6 shows the changes of the acid-strength and amount of acidic sites due to grinding. The acid-strength of untreated material was between +3.3 and +1.5 in pKa unit, and its acidity was very small. In contrast, the acidstrength of sample treated for 6 hours became stronger than -3.0, and the acidities remarkably increased. The acidic strength and amount of the sample treated for 12 hours became lower.

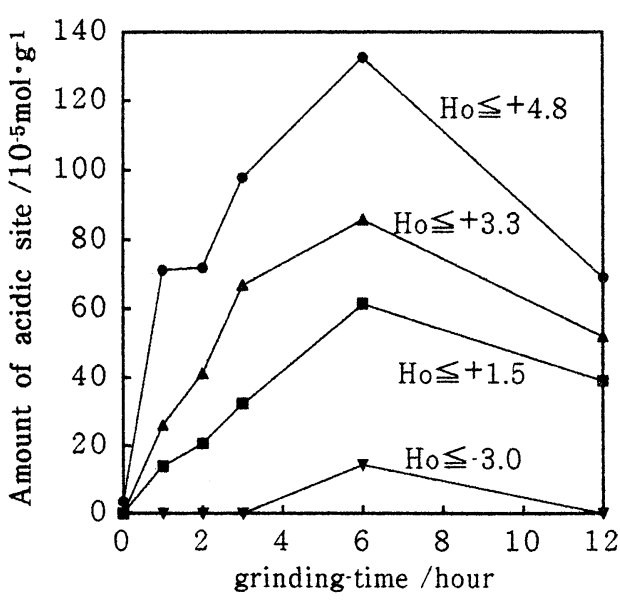

FIGURE 6 Acidities of $\mathrm{NdP}_{5} \mathrm{O}_{14}$ treated with grinding-mill.

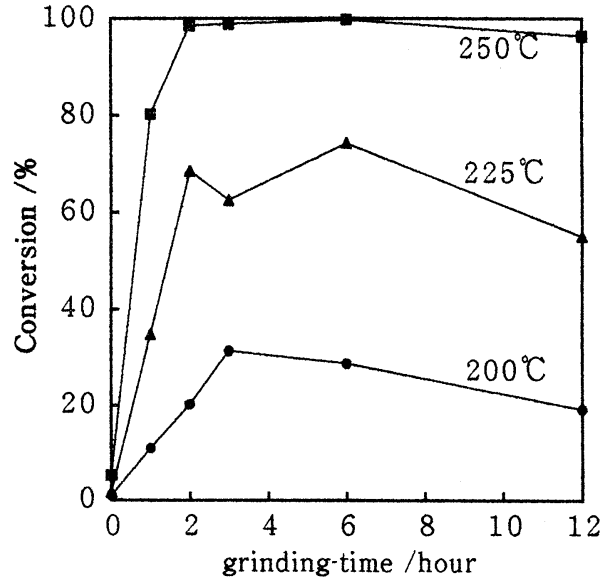

FIGURE 7 Conversion of 2-propanol to propylene over $\mathrm{NdP}_{5} \mathrm{O}_{14}$ treated with grinding-mill. 
Figure 7 shows the conversion of 2-propanol to propylene over ultraphosphates at $200^{\circ} \mathrm{C}, 225^{\circ} \mathrm{C}$ and $250^{\circ} \mathrm{C}$. Although at $250^{\circ} \mathrm{C}$ the ultraphosphate untreated converted $5.2 \%$ of 2 -propanol into propylene, the sample treated for 1 hour transformed $80.2 \%$ of 2 -propanol into propylene. The sample treated for 6 hours had the best catalytic activities.

The catalytic properties of $\mathrm{LaP}_{5} \mathrm{O}_{14}$ and $\mathrm{CeP}_{5} \mathrm{O}_{14}$ were examined in the same method, and obtained similar results. Only CeP5O14 treated for 12 hours produced a little acetone with propylene.

\section{SUMMARY}

By grinding, the intensity of X-ray diffraction lines of ultraphosphate became smaller and its P-O-P bonding changed to P-O-H bonding. The reforming based on these mechanochemical effects enlarged the catalytic abilities of rare-earth ultraphosphates.

\section{REFERENCE}

1) A. Durif, CRYSTAL CHEMISTRY OF CONDENSED PHOSHATES,

(Plenum Publishing Corp., New York, 1995), Chap.6, pp.359-374.

2) H. Honda , I. Soc. Mat. Sci. Jpn, 46, 703 (1997).

3) T. Kubo, Mechanochemistry Gairon, (Tokyo kagaku dojin , Tokyo , 1978), Chap.9 Sec.5, pp.176-190.

4) M. Tsuhako, S. Ikeuchi, T. Matsuo, I. Motooka, and M. Kobayashi, Bull. Chem. Soc. Jpn., 52,1034 (1979).

5) Y. Hikichi, T. Sasaki , K. Murayama , T. Nomura, and M. Miyamoto , I. Am. Ceram. Soc, , 72(6), 1073, (1989).

6) H. Nariai , I. Motooka , M. Doi , and M. Tsuhako, Bull. Chem. Soc. Ipn. , 58,379 (1985).

7) S. Kondo , T. Ishikawa, I. Abe, Science of Absorbtion, (Maruzen Ltd, Tokyo, 1991), Chap.3 Sec.2, pp.33-58.

8) O. Johnson, I. Phys. Chem. , 59,827 (1955).

9) H. Nariai, H. Taniguchi, H. Maki, and I. Motooka, Phosphorus Research Bulletin , 8, 119 , (1998).

10) D. E. C. Corbridge and E. J. Lowe, J. Chem. Soc, 493 (1954). 